\title{
Polyion complex micelle formed from tetraphenylethene containing block copolymer
}

\author{
Seong Min Lee and Woo-Dong Jang ${ }^{*}$ (D)
}

\begin{abstract}
Background: Polymeric micelles attract great attention in drug delivery and therapeutics. Various types of block copolymers have been designed for the application in biomedical fields. If we can introduce additional functional groups to the block copolymers, we can achieve advanced applications. In this regards, we tried to introduce aggregation induced emission enhancement (AIE) unit in the block copolymer.

Methods: The formation of polyion complex micelle was confirmed by dynamic light scattering and transmission electron microscopy. HeLa cells were incubated with polyion complex micelle and broad-band visible light using a halogen lamp (150 W) was irradiated to evaluate photocytotoxicity of polyion complex (PIC) micelle.

Results: For the design of functional polymeric micelle, aggregation induced emission enhancement unit was introduced in the middle of block copolymer. We newly synthesized a new type block copolymer (PEG-TPE-PEI) possessing tetraphenylethene (TPE) group, as an AIE unit, in the middle of polymeric segments of PEG and PEI, which successfully formed PIC micelle with DP. The formation of PIC micelle was confirmed by dynamic light scattering, $\zeta$ potential measurement and transmission electron microscopy.
\end{abstract}

Conclusions: PEG-TPE-PEI successfully formed PIC micelle by mixing with negatively charged dendrimer porphyrin. The PIC micelle exhibited photocytotoxicity upon illumination of broadband visible light.

Keywords: Aggregation induced emission, Polyion complex, Photodynamic therapy, Dendrimer, Polyoxazoline

\section{Background}

Polymeric micelles consist of hydrophobic inner core and hydrophilic outer shell attract great attention in drug delivery and therapeutics [1-3]. Various interactions can be utilized for the formation of polymeric micelles. A block copolymer having hydrophilic and hydrophobic blocks can form stable polymeric micelle in aqueous media. The difference in the internal and external properties of the micelle enables hydrophobic drugs to more bioavailable when used in the body. A block copolymer having hydrophilic block and ionic block also can form stable polyion complex (PIC) micelle when it interact with oppositely charged polymers $[4,5]$. For the formation of stable PIC micelle, block copolymers with poly(ethylene glycol) (PEG) and electrolytes such as poly(L-lysine) (PLL), poly(L-glutamate), and polyethyleneimine (PEI) have

\footnotetext{
* Correspondence: wdjang@yonsei.ac.kr

Department of Chemistry, Yonsei University, 50 Yonsei-ro, Seodaemun-gu, Seoul 03722, Republic of Korea
}

been conjugated. For example, PEG-b-PLL has been used for the formation of DNA- or dendrimer-containing PIC micelle [6-8]. Especially, negatively charged dendrimer porphyrin (DP)-containing PIC micelle was extensively studied for the application in photodynamic therapy [9-16].

Aggregation induced emission (AIE) is anomalous photophysical phenomenon that observed in several organic fluorophores [17-19]. Generally, organic fluorophores having planar structure show collisional quenching behaviors in high concentration. By the formation of aggregates, most organic fluorophores become non-fluorescent. However, some organic fluorophores having rotatable groups show enhanced fluorescence emission by restricted molecular motion at solid state. Tetraphenylethene (TPE) group would be a typical example of AIE moiety. The phenyl units in TPE can be freely rotate in solution state through propeller motion. Therefore, the fluorescence emission of TPE in solution 
state is very weak because the excitation energy is released through non-radiative decay pathway. In contrast, the aggregate of TPE sterically restrict molecular motion of the phenyl units. Therefore, the fluorescence emission of TPE can be increased by aggregation.

\section{Methods}

\section{Materials and measurements}

All commercially available reagents were reagent grade and used without further purification. $\mathrm{CH}_{2} \mathrm{Cl}_{2}$, hexane, and tetrahydrofuran (THF) were freshly distilled before each use. Recycling preparative SEC was performed on a LC-9201 (JAI, Tokyo, Japan) instrument equipped with JAIGEL-1H, JAIGEL-2H, and JAIGEL-3H columns using $\mathrm{CHCl}_{3}$ as the eluent. UV-Vis absorption spectra were measured using a V-660 spectrophotometer (JASCO, Tokyo, Japan) equipped with a thermostatic cell holder coupled with a controller (ETCS-761, JASCO, Tokyo, Japan) at $30{ }^{\circ} \mathrm{C}$. Fluorescence spectra were measured by a JASCO FP-6300 spectrophotometer equipped with a thermostatic cell holder (ETC-273 T, JASCO, Tokyo, Japan) coupled with a controller (ETC-273 T, JASCO, Tokyo, Japan) at $30{ }^{\circ} \mathrm{C}$. All fluorescence spectra were measured using under-400 nm-cut off filter over detector and excitation wavelength in all measurements is fixed at $365 \mathrm{~nm}$. All spectral measurements were carried out using a quartz cuvette with a path length of $1 \mathrm{~cm} .{ }^{1} \mathrm{H}-\mathrm{NMR}$ spectra were recorded using a Bruker DPX $400(400 \mathrm{MHz})$ spectrometer in $\mathrm{CD}_{2} \mathrm{Cl}_{2}$. Analytical SEC was performed on a JASCO HPLC equipped with HF-403HQ and HF-404HQ columns (Shodex, Tokyo, Japan) using THF as the eluent. MALDI-TOF-MS was performed on a Bruker Daltonics LRF20 with dithranol as the matrix. The DLS measurements were performed using a Photal dynamic laser scattering DLS-7000 spectrometer (Otsuka Electronics Co., Ltd., Osaka, Japan) equipped with GLG3050 $488 \mathrm{~nm}$ Ar laser (NEC Co., Ltd., Japan) and/or Zetasizer Nano ZS-90 (Malvern Co., Ltd., USA) with $532 \mathrm{~nm}$ laser irradiation.

\section{Synthesis}

1. To a $500 \mathrm{~mL}$ two necked round bottom flask, phenylboronic acid (10.0 g, $82.0 \mathrm{mmol}), \mathrm{Pd}(\mathrm{OAc})_{2}$ $(0.122 \mathrm{~g}, 0.5 \mathrm{mmol})$, triphenylphosphine $(0.286 \mathrm{~g}$, $0.001 \mathrm{mmol}), \alpha$-chloro-p-xylene $(7.17 \mathrm{~mL}$, $0.041 \mathrm{mmol})$ and $\mathrm{K}_{3} \mathrm{PO}_{4}(23.18 \mathrm{~g}, 0.110 \mathrm{mmol})$ was added into $150 \mathrm{~mL}$ toluene under $\mathrm{N}_{2}$ atmosphere, and stirred for $20 \mathrm{~h}$ at $80^{\circ} \mathrm{C}$. Then, the reaction mixture was cooled to room temperature and washed with $\mathrm{NaOH}$ solution $(1.00 \mathrm{M})$. The organic layer was purified by flash column chromatography on silica gel using hexane and dichloromethane to afford phenylmethane derivatives. $8.85 \mathrm{~g}(64 \%)$ as a yellow liquid. ${ }^{1} \mathrm{H}$ NMR (400 MHz, $\mathrm{CD}_{2} \mathrm{Cl}_{2}$ ) $\delta=7.66-7.15$ (m, $9 \mathrm{H}), 3.98$ (s, $2 \mathrm{H}), 2.361$ (s, $3 \mathrm{H})$. 2. To a 4-methyl diphenylmethane (3.5 g, $19.2 \mathrm{mmol}$ ) solution in THF under $\mathrm{N}_{2}$, n-butyllithium $(17 \mathrm{~mL}$, 1.6 $\mathrm{M}$ in hexane, $27.2 \mathrm{mmol}$ ) was slowly added by syringe with stirring at $0{ }^{\circ} \mathrm{C}$ for $1 \mathrm{~h}$. Then, 4methylbenzophenone $(5.00 \mathrm{~g}, 25.4 \mathrm{mmol})$ was slowly added, and the solution was further stirred for overnight at room temperature. The reaction mixture was quenched with saturated $\mathrm{NH}_{4} \mathrm{Cl}$ solution and then extracted with $\mathrm{CH}_{2} \mathrm{Cl}_{2}$. The organic layers are collected and concentrated. The crude product and p-toluenesulfonic acid $(0.2 \mathrm{~g})$ are dissolved into $100 \mathrm{~mL}$ of toluene. The mixture was heated to reflux for $4 \mathrm{~h}$. After cooled down to room temperature, the reaction mixture was extracted with $\mathrm{CH}_{2} \mathrm{Cl}_{2}$. The combined organic layer was was purified by silica-gel chromatography using hexane as eluent to give $\mathbf{2}$ as white solid (1.99 g). ${ }^{1} \mathrm{H}$ NMR $\left(\mathrm{CD}_{2} \mathrm{Cl}_{2}, 400 \mathrm{MHz}\right)$, $\delta=7.52-6.97(\mathrm{~m}, 18 \mathrm{H}), 2.29-2.26(\mathrm{t}, 6 \mathrm{H})$.

3. To a $\mathrm{CCl}_{4}$ solution of $2(0.70 \mathrm{~g}, 1.94 \mathrm{mmol})$ and $\mathrm{N}$-bromosuccimide $(0.70 \mathrm{~g}, 3.88 \mathrm{mmol})$, benzoyl peroxide $(2 \mathrm{mg})$ was added and refluxed for $12 \mathrm{~h}$. The mixture was extracted with $\mathrm{CH}_{2} \mathrm{Cl}_{2}$ and water. The combined organic layers was dried over magnesium sulfate, and evaporated under reduced pressure. The crude product was dissolved in $\mathrm{N}, \mathrm{N}$-dimethylformamide and sodium azaide $(0.041 \mathrm{~g})$ was added. And the mixture was stirred for $5 \mathrm{~h}$ at $50{ }^{\circ} \mathrm{C}$. Then, the reaction mixture was extracted with $\mathrm{CH}_{2} \mathrm{Cl}_{2}$. The crude product was purified by silica-gel chromatography using hexane as eluent to give 3 as yellow solid $(0.154 \mathrm{~g}, 18 \%$ yield). ${ }^{1} \mathrm{H}$ NMR $\left(\mathrm{CD}_{2} \mathrm{Cl}_{2}, 400 \mathrm{MHz}\right), \delta=7.13-7.011$ (m, $18 \mathrm{H}), 4.27$ (s, $4 \mathrm{H})$.

\section{PiPrOx}

An acetonitrile solution $(15 \mathrm{~mL})$ of methyl ptoluenesulfonate $(0.28 \mathrm{~mL}, 1.62 \mathrm{mmol})$ and iPrOx $(10 \mathrm{~mL}$, $73.2 \mathrm{mmol}$ ) was stirred at $40{ }^{\circ} \mathrm{C}$ under $\mathrm{N}_{2}$ atmosphere and monitored with analytical SEC and MALDI-TOF-MS. When the reaction was completed, the reaction mixture was cooled to room temperature and further stirred for 4 days after addition of $\mathrm{N}$-methyl propargylamine $(0.183 \mathrm{~mL}, 112 \mathrm{mmol})$ to introduce propargyl group at the $\omega$-terminal. The solution of PiPrOx was purified via dialysis for 2 days against distilled water and then recovered by lyophilization to obtain PiPrOx as white powder (5.30 g, 90\%). ${ }^{1} \mathrm{H}-\mathrm{NMR}\left(400 \mathrm{MHz}, \mathrm{CD}_{2} \mathrm{Cl}_{2}, 25{ }^{\circ} \mathrm{C}\right.$ ) $\delta$ (ppm): 3.48 (broad s; $-\mathrm{CH}_{2}-\mathrm{CH}_{2}$ - on the polymer backbone), 3.06 (s; terminal $-\mathrm{CH}_{3}$ ), 2.96-2.54 (two broad s; $-\mathrm{CH}$ - on the polymer side chain), $2.36-2.26$ (two broad $\mathrm{s} ;-\mathrm{NCH}_{2}$ - on the polymer side chain), 1.07 (strong broad s; $-\mathrm{CH}_{3}$ on the polymer side chain). 


\section{TPE-PiPrOx}

A mixture solution of 3 (160 mg, $0.032 \mathrm{mmol}$ ), PiPrOx (1.28 g, $0.40 \mathrm{mmol}$ ) and copper(II) sulfate pentahydrate (201.6 mg, $0.67 \mathrm{mmol}$ ) in $20 \mathrm{~mL}$ of THF were placed in round bottom flask. Aqueous solution $(1 \mathrm{~mL})$ of sodium ascorbate (713 mg, $0.67 \mathrm{mmol}$ ) was added and refluxed for 1 days. The mixture was washed with brine and water. The organic layer was concentrated in vacuo and purified with recycling preparative SEC and then recovered by lyophilization to obtain TPE-PiPrOx as yellow powder (123 mg). ${ }^{1} \mathrm{H}-\mathrm{NMR}\left(400 \mathrm{MHz}, \mathrm{CD}_{2} \mathrm{Cl}_{2}, 25{ }^{\circ} \mathrm{C}\right.$ ) $\delta$ (ppm): 7.28 (broad s, $6 \mathrm{H}$; - $\mathrm{CH}$ on TPE), 7.1 (broad s, $12 \mathrm{H}$; $-\mathrm{CH}$ in TPE), 4.23 (broad s, $2 \mathrm{H} ;-\mathrm{CH}_{2}-\mathrm{N}_{3}$ ), 3.48 (broad s; $-\mathrm{CH}_{2}-\mathrm{CH}_{2}$ - on the polymer backbone), 3.06 (s; terminal $-\mathrm{CH}_{3}$ ), 2.96-2.54 (two broad s; $-\mathrm{CH}$ - on the polymer side chain), 2.36-2.26 (two broad s; $-\mathrm{NCH}_{2}$ - on the polymer side chain), 1.07 (strong broad s; $-\mathrm{CH}_{3}$ on the polymer side chain).

\section{PEG-TPE-PiPrOx}

To a mixture solution of TPE-PiPrOx $(500 \mathrm{mg}$, $10.0 \mathrm{mmol}$ ), propargyl-bearing PEG (583 mg, $11.6 \mathrm{mmol}$ ), and copper(II) sulfate pentahydrate (63 mg, $35 \mathrm{mmol}$ ) in $5 \mathrm{~mL}$ of THF, aqueous solution $(1.5 \mathrm{~mL})$ of sodium ascorbate $(223 \mathrm{mg}$ ) was added and refluxed for 1 days. Then, the reaction mixture was washed with brine and water. The combined organic layer was concentrated in vacuo and purified with recycling preparative SEC and then recovered by lyophilization to obtain PEG-TPEPiPrOx as yellow powder (123 mg, 18\%). ${ }^{1} \mathrm{H}-\mathrm{NMR}$ (400 MHz, $\left.\mathrm{CD}_{2} \mathrm{Cl}_{2}, 25^{\circ} \mathrm{C}\right) \delta(\mathrm{ppm}): 7.4(\operatorname{broad} \mathrm{s}, 10 \mathrm{H}$; $-\mathrm{CH}$ on TPE), 7.1 (broad $\mathrm{s}, 8 \mathrm{H}$; $-\mathrm{CH}$ in TPE), 3.69 (broad s; $-\mathrm{CH}_{2}-\mathrm{CH}_{2}$ - on the PEG backbone), 3.43 (s; broad s; $-\mathrm{CH}_{2}-\mathrm{CH}_{2}$ - on the iPrPOx backbone), 3.33 (broad s; terminal $-\mathrm{CH}_{3}$ on the PEG backbone), 3.06 (s; terminal $-\mathrm{CH}_{3}$ ), 2.96-2.54 (two broad s; $-\mathrm{CH}$ - on the iPrPOx side chain), 2.36-2.26 (two broad s; - NCH2- on the polymer side chain), 1.07 (strong broad s; $-\mathrm{CH}_{3}$ on the polymer side chain).PEG-TPE-PEI: PEG-TPEPiPrOx (50 mg) was dissolved in $5.00 \mathrm{M}$ of aqueous $\mathrm{HCl}(10.0 \mathrm{~mL})$ and refluxed for 1 days. The $2.5 \mathrm{M}$ $\mathrm{NaOH}$ solution was added to mixture until $\mathrm{pH}$ reached to 8.0. PEG-TPE-PEI was recovered by lyophilization as a red powder. ${ }^{1} \mathrm{H}-\mathrm{NMR}\left(400 \mathrm{MHz}, \mathrm{CD}_{2} \mathrm{Cl}_{2}, 25^{\circ} \mathrm{C}\right) \delta$ (ppm): 7.27 (broad s, $10 \mathrm{H}$; $-\mathrm{CH}$ on TPE), 7.1 (broad s, $8 \mathrm{H} ;-\mathrm{CH}$ in TPE), 3.69 (broad $\mathrm{s} ;-\mathrm{CH}_{2}-\mathrm{CH}_{2}$ - on the PEG backbone), 3.43 ( $\mathrm{s}$; broad $\mathrm{s}$; $-\mathrm{CH}_{2}-\mathrm{CH}_{2}$ - on the PEI backbone), 3.33 (broad $\mathrm{s}$; terminal $-\mathrm{CH}_{3}$ on the PEG backbone), 3.06 (s; terminal $-\mathrm{CH}_{3}$ ), 1.87-1.78 (two broad $\mathrm{s} ;-\mathrm{NCH}_{2}$ - on the PEI side chain).

\section{Preparation of PIC micelle}

PIC micelles were obtained from negatively charged DP and PEG-TPE-PEI. In a typical procedure, the PEG-
TPE-PEI was dissolved in an aqueous $\mathrm{NaH}_{2} \mathrm{PO}_{4}$ solution and added to an aqueous solution of DP in PBS buffer to give a solution containing PIC micelles. The ratio of positive charge to negative charge was fixed at 1:1.

\section{Cytotoxicity assay}

HeLa cells were used in the cell culture studies. In the cytotoxicity assay, different concentration of PEG-TPEPEI, DP, and PIC micelle in Dulbecco's modified Eagle's medium (10\% FBS, MEM) were added to cells in 96-wll culture plates $(n=4)$. After a $24 \mathrm{~h}$ incubation at $37^{\circ} \mathrm{C}$, cells were washed with PBS, and then plates were photoirradiated for 15-60 min with broad-band visible light using a halogen lamp (150 W) equipped with a filter passing light of 400-700 nm (fluence energy; 27-107 kJ/ $\mathrm{m}^{2}$ ). The viability of the cells was evaluated using mitochondrial respiration via the 3-(4,5-dimethyl thiazole-2yl)-2,5-diphenyltetrazolium bromide cleavage assay (MTT assay) following incubation for $48 \mathrm{~h}$ after photoirradiation or washing in the case of the dark toxicity investigation.

\section{Results}

The preparation of PEG-TPE-PEI was summarized in Scheme 1. Briefly, poly(2-isopropyl-2-oxazoline) (PiPrOx) was prepared by living cationic polymerization of 2isopropyl-2-oxazoline using methyl $p$-toluenesulfonate as an initiator [20]. The living end group of PiPrOx was terminated with $N$-methylpropargylamine to introduce clickable propargyl end group [21]. Then, phenylboronic acid and $p$-chloromethyl toluene was coupled to obtain $\mathbf{1}$, which was further reacted with 4-methyl benzophenone and successive dehydration reaction was conducted to obtain 2. Azide-bearing TPE (3) was obtained from 2 via bromination and azide coupling reactions. PiPrOx was introduced to 3 by copper catalyzed click reaction [22]. Then, propargyl-bearing PEG was again introduced to the other azide group in TPE. Finally, the PiPrOx chain was hydrolyzed by acid treatment to convert PEI block. After the reaction, preparative GPC was applied to purify the block copolymers. All the products were characterized by ${ }^{1} \mathrm{H}$ NMR and size exclusion chromatography (SEC) measurements.

The number average molecular weight $(M n)$ and dispersity index $(\nexists)$ of PEG-TPE-PiPrOx were about $12,500 \mathrm{~g} / \mathrm{mol}$ and 1.08 , respectively, indicating narrow molecular weight distribution. Likewise, PEG-TPE-PEI also has very narrow molecular weight distribution, where $M \mathrm{n}$ and $\oslash$ values were about $8900 \mathrm{~g} / \mathrm{mol}$ and 1.05, respectively (Fig. 1). The elution time of PEGTPE-PEI was longer than that of PEG-TPE-PiPrOx.

Anionic DP was prepared by previously reported procedure. The structure of DP is shown in Fig. 2. Because PEG-TPE-PEI has cationic polymer block, we have 

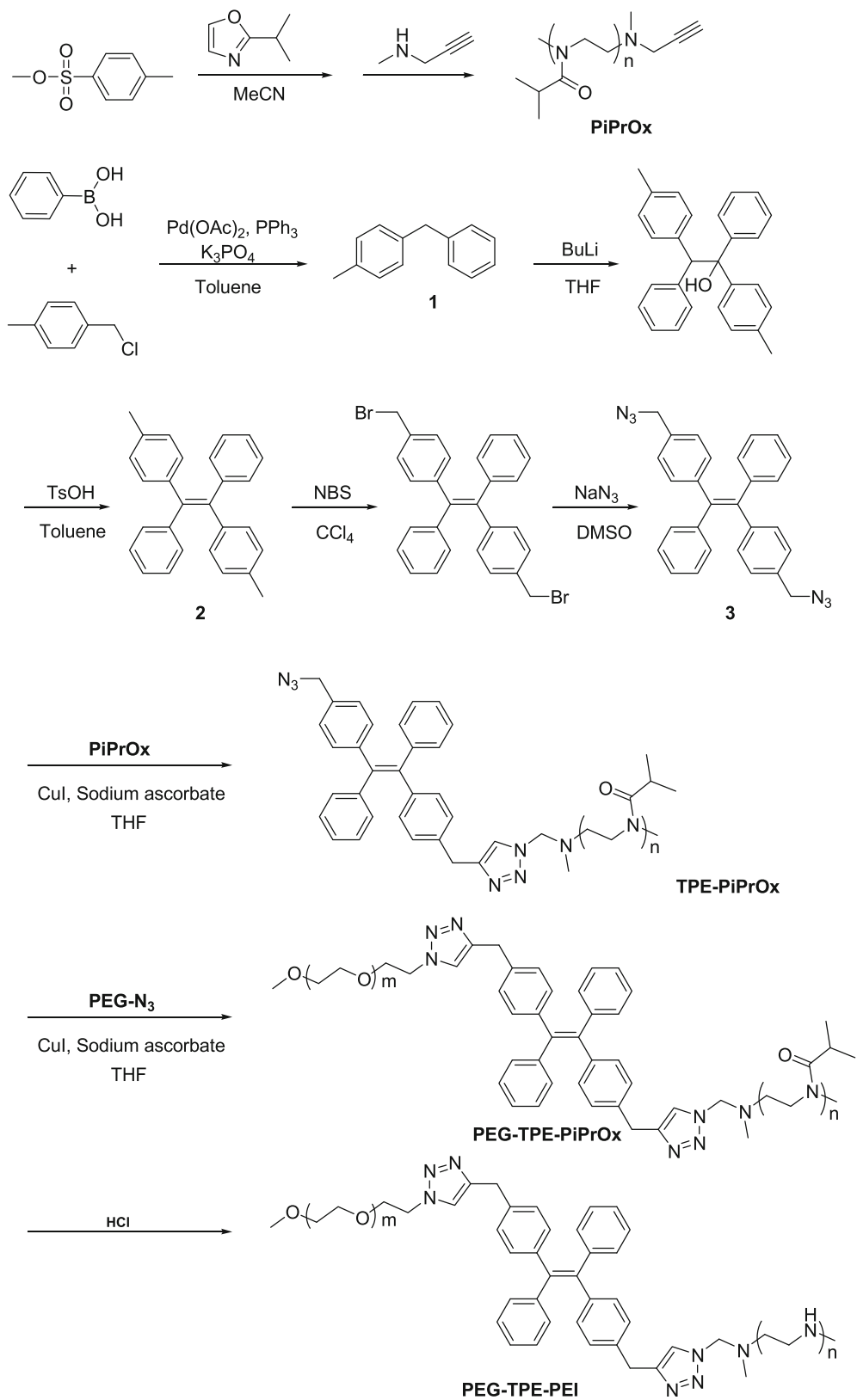

Scheme 1 Synthesis of PEG-TPE-PEI

tested the formation of PIC micelle with the anionic DP. For the formation of PIC micelle, PEG-TPE-PEI (13.0 $\mathrm{mg})$ and DP $(7.3 \mathrm{mg})$ was dissolved in $10 \mathrm{mM}$ phosphate buffered saline (PBS, pH 7.4) in a stoichiometric ratio of positive and negative charges, respectively. The formation of PIC micelle was confirmed by $\zeta$-potential and dynamic light scattering (DLS) measurements.

DLS measurement of PEG-TPE-PEI showed formation of nanoparticles with an average diameter of $119.2 \mathrm{~nm}$. The nanoparticle can be formed by hydrophobic attraction of TPE units. On the other hand, when we mixed PEG-TPE-PEI with DP in a 1:1 charge ratio, uniform sized PIC micelle with an average diameter of $87 \mathrm{~nm}$ was formed. The $\zeta$ potential of DP was confirmed to be $-16.87 \mathrm{mV}$. But the PIC micelles showed $-4.12 \mathrm{mV}$ of surface potential. The reduced $\zeta$ potential values indicates the surface of PIC micelle covered by PEG segments. The formation of PIC micelle was again confirmed by transmission electron microscopy (TEM) measurement. As shown in Fig. 3, TEM image of PIC micelles $(1.5 \mathrm{mg} / \mathrm{mL})$ showed spherical shapes with approximately $100-200 \mathrm{~nm}$ sizes.

Figure 4a shows absorption and emission spectra of 3 and DP. Because the emission of $\mathbf{3}$ is well overlaps with the Soret absorption band of DP, we can expect efficient 


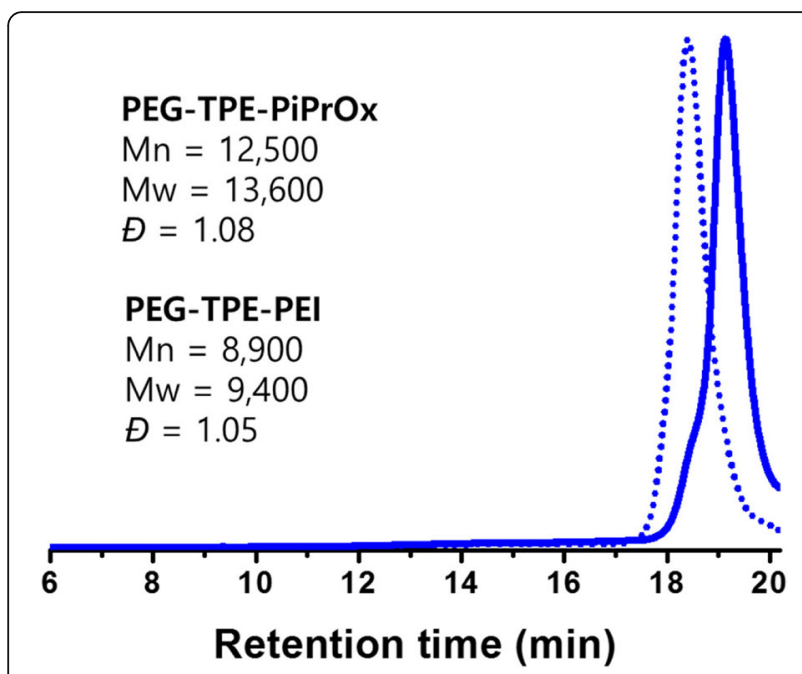

Fig. 1 SEC profiles of PEG-TPE-PiPrOx and PEG-TPE-PEI

energy transfer from TPE to DP. As expected, the fluorescence of PIC micelle exhibited stronger fluorescence emission than that of DP alone, indicating the efficient energy transfer.

Because DP is an effective photosensitizer for photodynamic therapy (PDT), we have measured photocytotoxicity of the PIC micelle. The PDT efficacy was confirmed by cell viability measurement using MTT assay for various light irradiation time and concentration. HeLa cells (3000 cells/well) were incubated with PIC micelle and DP for
24 h. A broad-band visible light from a light emitting diode (LED; incident energy $132 \mathrm{kJcm}^{-2}$ ) was illuminated to the cells for $0,30,60$, and $90 \mathrm{~min}$, respectively. Under dark conditions, the cell viability for both DP and PIC micelle containing well were almost negligible, whereas strong cytotoxicity was observed for both DP and PIC micelle containing well by increasing light exposure time (Fig. 5).

\section{Discussion}

We newly synthesized a new type block copolymer (PEG-TPE-PEI) possessing TPE group as an AIE unit in the middle of polymeric segments of PEG and PEI, which successfully formed PIC micelle with DP [23-26]. In general, fluorescent dyes show collisional quenching behaviors highly concentrated state. Therefore, most fluorescent dyes become non-fluorescent when they are encapsulated into the micellar formulation. However, TPE groups can show enhanced fluorescence emission by the formation of polymeric micelle. Such aspect will give great advantages for the monitoring of micelles [17-19].

Through living cationic polymerization, PiPrOx was successfully synthesized. PiPrOx and PEG were introduced to the azide-bearing TPE by copper catalyzed click reaction. PiPrOx chain was hydrolyzed by acid treatment to convert PEI block. All the products were characterized by ${ }^{1} \mathrm{H}$ NMR and SEC measurements. The results of ${ }^{1} \mathrm{H}$ NMR and SEC measurement indicated

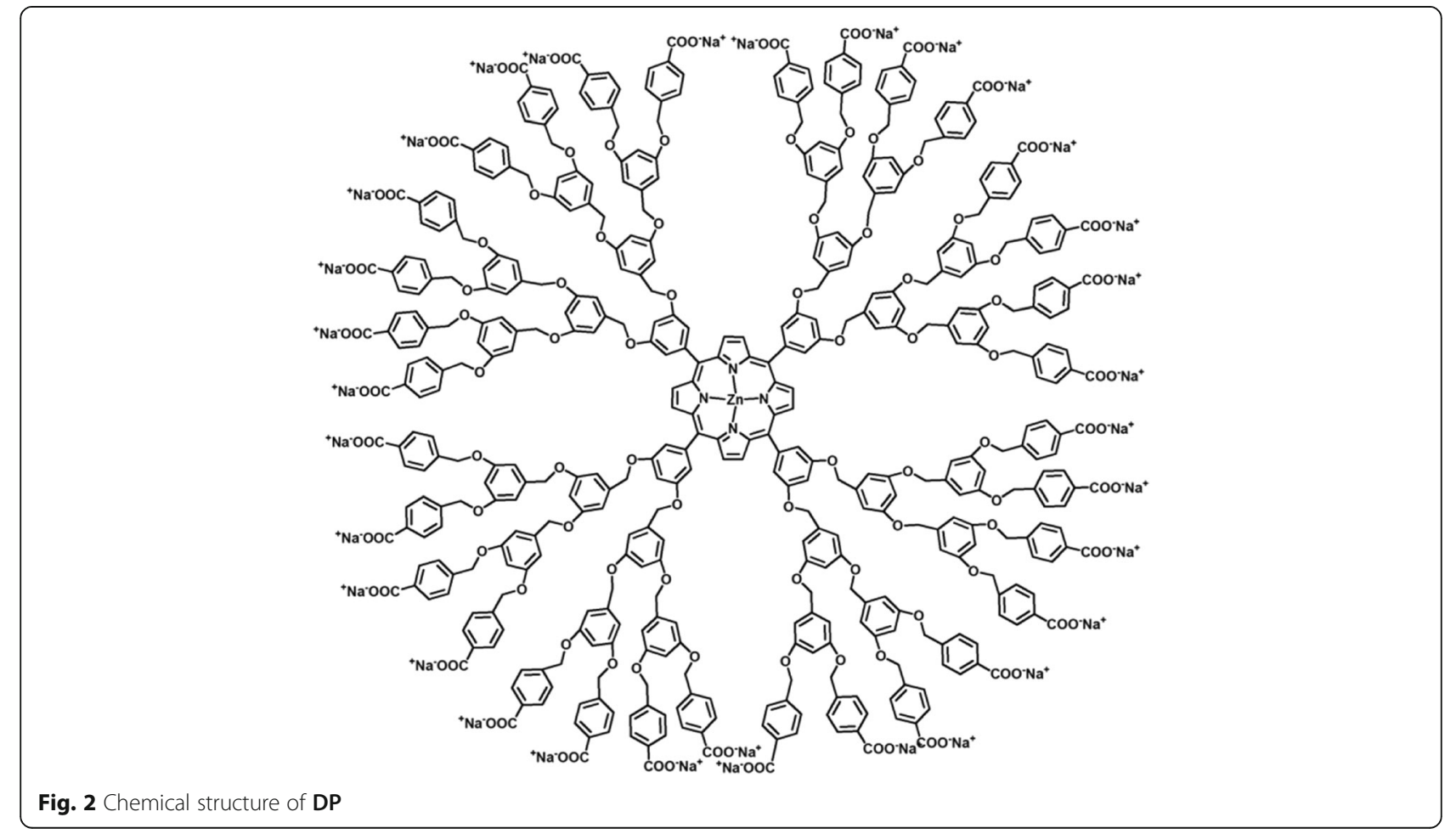




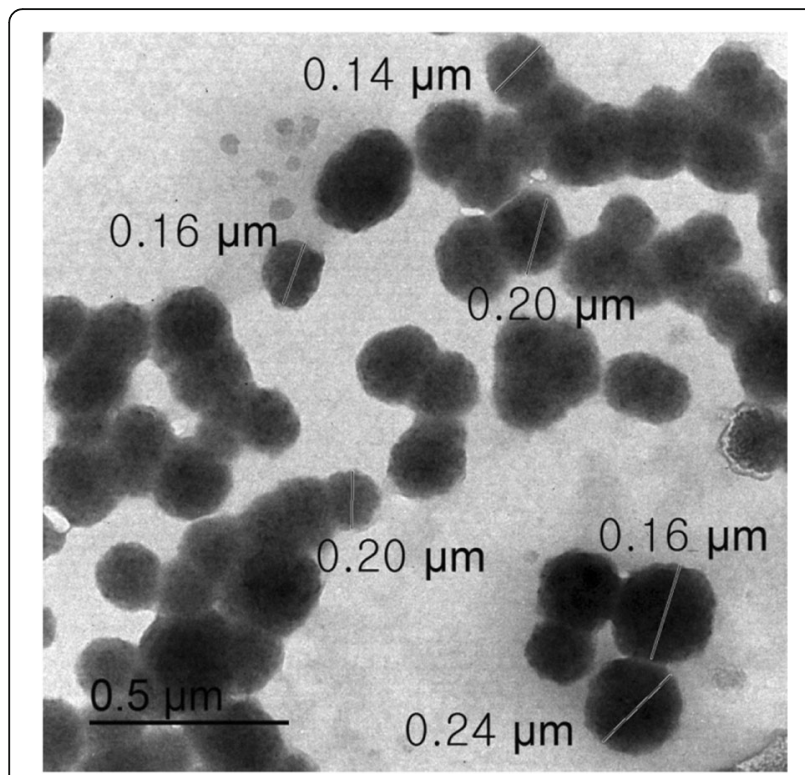

Fig. 3 TEM image of PIC micelle

narrow molecular weight distribution of PEG-TPEPiPrOx and PEG-TPE-PEI.

The formation of PIC micelle was confirmed by $\zeta$-potential and dynamic light scattering (DLS) measurements. The result of DLS measurement indicated the formation of uniform sized PIC micelle. The change of $\zeta$ potential also indicated the successful formation of PIC micelles. TEM observation further evidenced the formation of uniform PIC micelles.

Because the absorption band of DP overlaps with the emission of TPE unit, PIC micelle exhibited enhanced

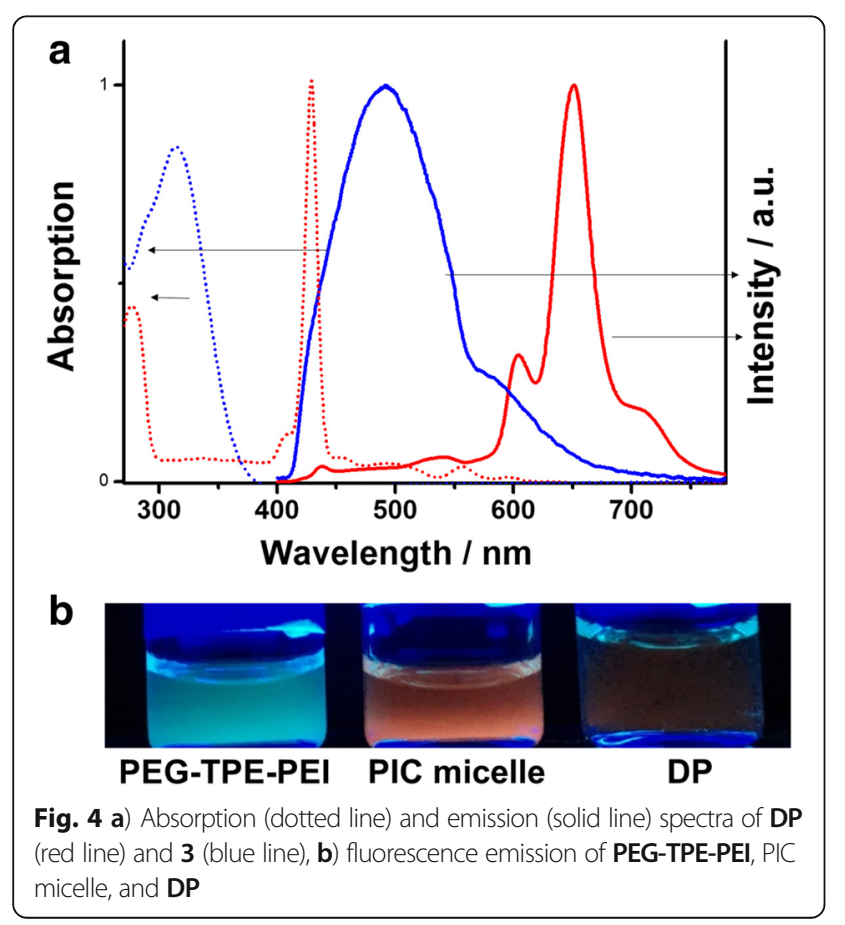

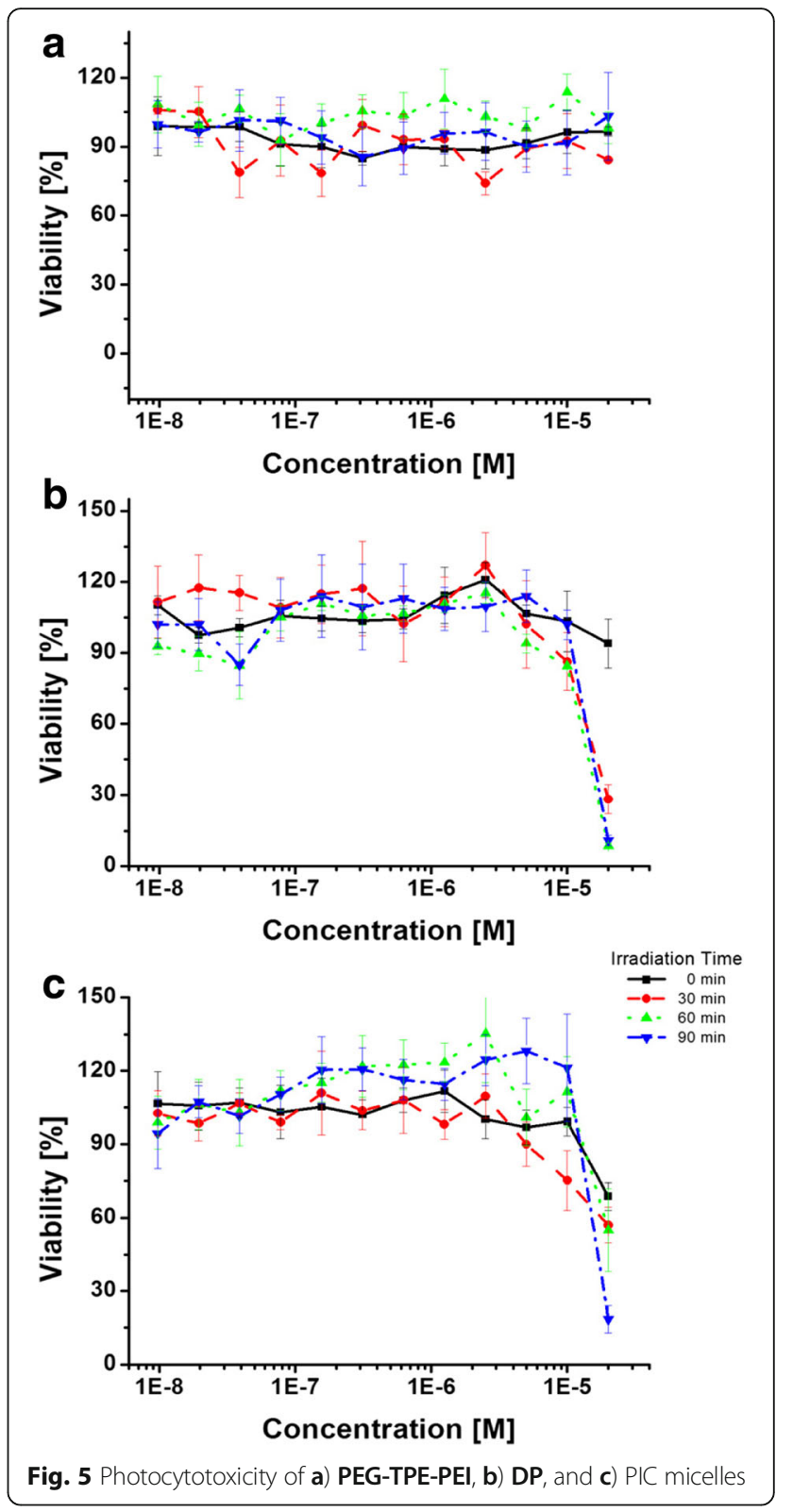

fluorescence emission than that of DP alone due to the energy transfer from TPE units to DPs. The DP-encapsulated PIC micelle exhibited strong cytotoxicity under broad-band visible light illumination. The PIC micelle exhibited almost comparable photocytotoxicity with DP. Because PEG-TPE-PEI successfully formed PIC micelle with DP, other anionic macromolecules can be encapsulated by electrostatic interaction with positively charged PEI block in PEG-TPE-PEI.

\section{Conclusion}

We have prepared a new type block copolymer (PEGTPE-PEI) possessing TPE group as an AIE unit in the middle of polymeric segments of PEG and PEI, which 
successfully formed PIC micelle with DP. The formation of PIC micelle was confirmed by dynamic light scattering, $\zeta$ potential measurement and transmission electron microscopy. The PIC micelle exhibited photocytotoxicity upon illumination of broadband visible light. Because the TPE group can emit enhanced fluorescence, the formation of polymeric micelle can be directly observed. If we use non-fluorescent drug to form polymeric micelle, the AIE phenomena can be greatly useful.

\section{Abbreviation}

AlE: Aggregation induced fluorescence enhancement; DLS: Dynamic light scattering; DP: Dendrimer porphyrin; LED: Light emitting diode; PDT: Photodynamic therapy; PEG: Poly(ehtyleneglycol; PEl: Polyethyleneimine; PIC: Polyion complex; PiPrOx: Poly(2-isopropyl-2-oxazoline); TEM: Transmission electron microscopy; THF: Tetrahydrofuran; TPE: Tetraphenylethane

\section{Acknowledgements}

Not applicable.

\section{Funding}

This work was supported by the Mid-Career Researcher Program (2014R1A2A1A10051083) funded by the National Research Foundation (NRF) of Korea, Ministry of Science, ICT \& Future.

\section{Availability of data and materials}

The datasets used and/or analysed during the current study. Are available from the corresponding author on reasonable request.

\section{Authors' contributions \\ S. M. Lee carried out all experiment under guidance of W.-D. Jang. Both authors read and approved the final manuscript.}

\section{Ethics approval and consent to participate}

Not applicable.

\section{Consent for publication}

Not applicable.

\section{Competing interests}

The authors declare that they have no competing interests.

\section{Publisher's Note}

Springer Nature remains neutral with regard to jurisdictional claims in published maps and institutional affiliations.

Received: 30 May 2017 Accepted: 20 September 2017

Published online: 10 October 2017

\section{References}

1. Kwon GS, Okano T. Polymeric micelles as new drug carriers. Adv Drug Deliv Rev. 1996;21:107-16.

2. Kataoka K, Harada A, Nagasaki Y. Block copolymer micelles for drug delivery: design, characterization and biological significance. Adv Drug Deliv Rev. 2001:47:113-31.

3. Sheikh Z, Hamdan N, Ikeda Y, Grynpas M, Ganss B, Glogauer M. Natural graft tissues and synthetic biomaterials for periodontal and alveolar bone reconstructive applications: a review. Biomater Res. 2017;21:9.

4. Harada A, Kataoka K. Formation of polyion complex micelles in an aqueous milieu from a pair of oppositely-charged block copolymers with poly(ethylene glycol) segments. Macromolecules. 1995;28:5294-9.

5. Yoon H, Dell EJ, Freyer JL, Campos LM, Jang W-D. Polymeric supramolecular assemblies based on multivalent ionic interactions for biomedical applications. Polymer. 2014;55:453-64.

6. Katayose S, Kataoka K. Water-soluble polyion complex associates of DNA and poly (ethylene glycol)-poly(l-lysine) block copolymer. Bioconjug Chem. 1997;8:702-7.
7. Nishiyama N, Iriyama A, Jang W-D, Miyata K, Itaka K, Inoue Y, et al. Lightinduced gene transfer from packaged DNA enveloped in a dendrimeric photosensitizer. Nat Mater. 2005;4:934-41.

8. Ideta R, Tasaka F, Jang W-D, Nishiyama N, Zhang G-D, Harada A, et al. Nanotechnology-based photodynamic therapy for neovascular disease using a supramolecular nanocarrier loaded with a dendritic photosensitizer. Nano Lett. 2005;5:2426-31.

9. Jang W-D, Selim KK, Lee C-H, Kang $\mathrm{H}-\mathrm{K}$. Bioinspired application of dendrimers: from bio-mimicry to biomedical applications. Prog Polym Sci. 2009;34:1-23.

10. Nishiyama N, Morimoto $Y$, Jang W-D, Kataoka K. Design and development of dendrimer photosensitizer-incorporated polymeric micelles for enhanced photodynamic therapy. Adv Drug Deliv Rev. 2009;61:327-38.

11. Jang W-D, Nakagishi Y, Nishiyama N, Kawauchi S, Morimoto Y, Kikuchi M, et al. Polyion complex micelles for photodynamic therapy: incorporation of dendritic photosensitizer excitable at long wavelength relevant to improved tissue-penetrating property. J Control Release. 2006;113:73-9.

12. Son KJ, Yoon HJ, Kim JH, Jang WD, Lee Y, Koh WG. Photosensitizing hollow nanocapsules for combination cancer therapy. Angew Chem Int Ed. 2011;50:11968-71.

13. Yoon $\mathrm{H}-J$, Jang W-D. Nanotechnology-based photodynamic therapy. J Porphyrins Phthalocyanines. 2013;17:16-26.

14. Jang W-D, Yim D, Hwang $\mathrm{H}$-H. Photofunctional hollow nanocapsules for biomedical applications. J Mater Chem B. 2014;2:2202-11.

15. Yoon H-J, Lim TG, Kim J-H, Cho YM, Kim YS, Chung US, et al. Fabrication of multifunctional layer-by-layer nanocapsules toward the design of theragnostic nanoplatform. Biomacromolecules. 2014;15:1382-9.

16. Lucky SS, Soo KC, Zhang Y. Nanoparticles in photodynamic therapy. Chem Rev. 2015;115:1990-2042

17. He L, Liu X, Liang J, Cong Y, Weng Z, Bu W. Fluorescence responsive conjugated poly (tetraphenylethene) and its morphological transition from micelle to vesicle. Chem Commun. 2015;51:7148-51.

18. Chen Y, Lam JW, Chen S, Tang BZ. Synthesis, properties, and applications of poly (ethylene glycol)-decorated tetraphenylethenes. J Mater Chem C. 2014;2:6192-8.

19. Ding D, Li K, Liu B, Tang BZ. Bioprobes based on AlE fluorogens. Acc Chem Res. 2013:46:2441-53.

20. Adams N, Schubert US. Poly(2-oxazolines) in biological and biomedical application contexts. Adv Drug Deliv Rev. 2007:59:1504-20.

21. Kim J-H, Koo E, Ju S-Y, Jang W-D. Multimodal stimuli-responsive poly(2isopropyl-2-oxazoline) with dual molecular logic gate operations. Macromolecules. 2015;48:4951-6.

22. Liang L, Astruc D. The copper (I)-catalyzed alkyne-azide cycloaddition (CuAAC)"click" reaction and its applications. An overview Coord Chem Rev. 2011;255:2933-45

23. Kim J-H, Yim D, Jang W-D. Thermo-responsive poly(2-isopropyl-2-oxazoline) and tetraphenylethene hybrids for stimuli-responsive photoluminescence control. Chem Commun. 2016:52:4152-5.

24. Hong Y, Lam JW, Tang BZ. Aggregation-induced emission. Chem Soc Rev. 2011:40:5361-88.

25. Hu R, Leung NL, Tang BZ. AIE macromolecules: syntheses, structures and functionalities. Chem Soc Rev. 2014:43:4494-562.

26. Lim C-K, Heo J, Shin S, Jeong K, Seo YH, Jang W-D, et al. Nanophotosensitizers toward advanced photodynamic therapy of cancer. Cancer Lett. 2013;334:176-87.

Submit your next manuscript to BioMed Central and we will help you at every step:

- We accept pre-submission inquiries

- Our selector tool helps you to find the most relevant journal

- We provide round the clock customer support

- Convenient online submission

- Thorough peer review

- Inclusion in PubMed and all major indexing services

- Maximum visibility for your research

Submit your manuscript at www.biomedcentral.com/submit 